\title{
Study of Effect of Nano-Silica on Strength and Durability Characteristics of High Volume Fly Ash Concrete for Pavement Construction
}

\author{
Bimal Kumar ${ }^{\text {a }}$, Sanjeev Sinha ${ }^{a^{*}}$, Hillol Chakravarty ${ }^{\mathrm{a}}$ \\ ${ }^{a}$ National Institute of Technology Patna, Mahendru, Patna-800005, Biha, India.
}

Received 02 March 2019; Accepted 09 June 2019

\begin{abstract}
Increasing demands of cement concrete for construction of rigid pavements motivates for the utilization of other sustainable waste cementitious materials. High volume fly-ash concrete (HVFAC) which is composed of more than 50\% fly-ash fulfils the aspiration of large volume of fly-ash which are produced world over. The disadvantage which the HVFAC has is its delayed gain of strength. Contemporary literature identifies nano-silica as the material which when added in small percentages in HVFAC has the potential to improve its strength and durability characteristics at an early age. The objective of the study is to investigate the strength and durability characteristics of HVFAC modified with addition of different percentages of nano-silica so that it can be used for construction of rigid pavements. The methodology of the study involves mix proportioning of HVFAC and introducing nano-silica powder in aqueous medium after mixing it thoroughly at 2500 $\mathrm{rpm}$. Various tests related to strength and durability was carried out after 28, 56 and 90 days age of concrete. The tests related to strength namely flexural strength, compressive strength and split tensile strength tests were carried out. Durability characteristics were evaluated by permeability, sorptivity and rapid chloride penetration tests and were confirmed by density and ultrasonic pulse velocity test. The test results show that the utilization of $2 \%$ nano-silica in HVFAC enhances the strength and durability characteristics to a level that are comparable to that of normal concrete after 28 days and thus, can be sustainably utilized for rigid pavement construction.
\end{abstract}

Keywords: Concrete; High Volume Fly-ash Concrete (HVFAC); Nano-silica; Strength; Durability.

\section{Introduction}

Concrete is the most widely used man made material in the world and is second only to water as the most utilized substance on the planet [1]. It is produced by mixing water, aggregates along with cementing material and at times admixtures in the required proportions. With the increase of population, economic development and quality of life of people, the consumption of concrete is bound to increase in future. It is estimated that about 25 billion tons of concrete are manufactured all over the world. The principal binding material for cement concrete is cement but its production is an energy intensive process. It is estimated that cement production contributes about $7 \%$ of the total carbon dioxide emission, leading to its detrimental effect on environment and human health [2]. China, India and USA are among the three largest cement producing countries [3]. Presently, with its inherent qualities, cement concrete is being used in large quantities for construction of rigid pavements and is generically called as pavement quality concrete (PQC).

Lately, large quantities of fly ash are being produced in coal based thermal power plants where it is arrested mostly in the electrostatic precipitators (ESP). It has been established that the fly ash possesses pozzolanic properties meaning

* Corresponding author: sanjeev@nitp.ac.in

http://dx.doi.org/10.28991/cej-2019-03091336

(C) 2019 by the authors. Licensee C.E.J, Tehran, Iran. This article is an open access article distributed under the terms and conditions of the Creative Commons Attribution (CC-BY) license (http://creativecommons.org/licenses/by/4.0/). 
thereby that the siliceous and aluminous material by themselves do not possess cementitious properties but in finely divided form and in presence of moisture chemically react with calcium hydroxide at ordinary temperatures to form compounds possessing cementitious properties. In spite of being produced in large quantities throughout the world, flyash is not being utilized to the same extent. About 120-150 million tons of coal fly ash was produced by coal based thermal power plants in India in 2014. This is followed by China, USA and Germany producing about 100,75 and 40 million tons respectively of fly-ash every year.

The fly-ash produced are not always of the same quality. Its quality depends on the coal being used. ASTM has classified fly ash into two classes as Class F and Class C. Class F fly ash are generally produced by burning anthracite or bituminous coal. These are called siliceous fly ash. They have pozzolanic property only. It contains 70 percent or more $\mathrm{SiO}_{2}, \mathrm{Al}_{2} \mathrm{O}_{3}, \mathrm{Fe}_{2} \mathrm{O}_{3}$. Reactive $\mathrm{CaO}$ content is less than 10 percent. Whereas Class $\mathrm{C}$ fly ash are produced by burning of lignite or sub bituminous coal. These are called calcareous fly-ash. These have both pozzolanic and cementitious properties. It contains 50 percent or less $\mathrm{SiO}_{2}, \mathrm{Al}_{2} \mathrm{O}_{3}, \mathrm{Fe}_{2} \mathrm{O}_{3}$. Reactive $\mathrm{CaO}$ content is not less than 10 percent. They should conform to various physical and chemical requirements specified by IS: 3812-2013 part-1.

Fly ash not only reduces water demand but also forms cement gels at later stage which contributes to strength and dense packing and reduction in its porosity of concrete. It reduces heat of hydration and thus, is suitable for mass concreting works. Micro cracks are also minimized by controlling temperature stress. Moreover, bleeding is reduced and durability by sulphate resistance is increased. Reduced alkali-aggregate reaction, reduced chloride penetration and carbonation are also observed. Fly-ash also acts as micro aggregate and gives volume stability to concrete. Thus, use of fly-ash promotes energy conservation and ecofriendly construction. However, early strength will be less than normal concrete [4].

The utilization of fly-ash in India and China are about 38\% and 45\% respectively. This shows that there is a need for increase in utilization of fly-ash as a resource material. Efforts are being made world-over for utilization of fly-ash for various construction purposes and codes of practices and guidelines have been set forth. However, the utilization of the fly-ash still remains limited and fly-ash in concrete rarely exceeds $30 \%$. High volume fly-ash concrete is an example of construction material used in harmony with sustainable development. As per the definition given by Mehta [5], a concrete having a minimum cement replacement level of $50 \%$ by fly ash is termed as high volume fly ash concrete (HVFAC). Even though the HVFAC have lower compressive strength, the long term compressive strength is comparable with regular concrete after 90 days because of late hydration of fly ash [6, 7]. Kumar et al. [8] have reported that HVFAC mixtures containing 50 to $60 \%$ fly-ash could be designed to fulfill the requirement of strength and durability suitable for pavement quality concrete. In order to allow use of large volume of fly-ash in conventional concrete application, Canada Centre for Mineral and Energy Technology (CANMET) first introduced research studies on concrete containing 50 percent or more Class-F fly ash. Here both physical and chemical factors combine to give better resistance, durability and strength of concrete. The HVFAC has the advantage of replacement of energy intensive material, cement with that of fly-ash to the order of $50 \%$ or more making it economical and sustainable. HVFAC gains significant strength from $28^{\text {th }}$ to 90 days. Through the early strength is low but at later stages it provides better strength and durability requiring less maintenance. In spite of sustainable nature of HVFAC, it has not gained popularity in utilization for road construction because of its lower initial strength as it shall need longer time after casting to open for traffic. Results have shown that nanotechnology can be one of the ways to deal with such situation. Nanotechnology can be defined as the design, characterization, production and application of structures, devices and systems by controlling shape and size of any material at the nano-scale. Studies have shown that nanomaterials such as carbon nanotubes, nano titanium dioxide, nano silica, nano zinc oxide, nano aluminum oxide and nano iron oxide to have improved strength and durability characteristics in various types of concrete $[9,10]$.

Despite all these superior qualities HVFAC cannot be used effectively for concrete roads due to its lesser early strength. Hence modification is sine-qua-non for achievement of high early strength and therefore, in the present study, nano materials are added in concrete to modify various properties at nano level. Micro structure and water permeability of concrete incorporating nano silica in cement were studied and it was found that concrete with nano silica and fly ash has earlier pozzolanic reactions than concrete incorporating only fly ash and more $\mathrm{C}-\mathrm{S}-\mathrm{H}$ gel or hydration product was found [11]. It had a dense structure and its water permeability was also found to be less.

Effects of nano silica in concrete with high volume fly ash or slag were also studied [12]. Compressive strength was enhanced. Heat of hydration was more and pozzolanic reactions started at an early stage with nano $\mathrm{SiO}_{2}$. Again dormant period or inactive period was reduced. Structure was found to be densified with reduced porosity and increase of chloride resistance. It was found that use of nano-silica on sludge/fly ash mortars, compensates the negative effects associated to sludge incorporation in terms of setting time and initial strength [13]. It was also reported that nano-silica addition led to an increase of strength by 15-20\% [14]. All researchers found enhancement in durability properties due to nano particle addition. Chloride penetration, permeability decreased. Sulfate resistance was increased.

Effect of nano $\mathrm{SiO}_{2}$ on mechanical and Microstructural properties of ultra-high performance cementitious composite was studied [15]. It was found that optimum quantity of nano silica added was $3 \%$. After that value strength begins to 
decrease. Nano silica addition was done in 3 proportions i.e. 1, 3, 5\%. Compressive strength for these proportions increased by $13.33,26.66,20 \%$ for 28 days and $15.58,29.87,20.77 \%$ for 90 days respectively with reference to normal concrete. Similarly for flexural strength was increased by 5.88, 11.76 and $8.82 \%$ respectively at 28 days age for the above mentioned proportions. Similar trend was also observed for 90 days. Quercia et al. [16] worked on SCC modification by use of amorphous nano silica. Nano silica was added in two forms i.e. colloidal and powder form and strength and workability analysis was done. It was found that addition of $3.8 \%$ nano silica both colloidal and powder improves strength of SCC. Addition of nano silica resulted in homogeneous microstructure.

Durability aspects of SCC containing nano $\mathrm{SiO}_{2}$ and $\mathrm{Nano}_{\mathrm{Fe}} \mathrm{O}_{3}$ was studied [17]. The amount of fly ash was $25 \%$ of the cement in all mixtures. The proportion of Nanoparticles amount used was considered at ratios corresponding to 1 , 2, 3, 4 and 5 percent weight of binder for all mixtures. For nano silica optimum dosage was found to be $4 \%$ and $2 \%$ was found to be the optimum dosage for nano $\mathrm{Fe}_{2} \mathrm{O}_{3}$. Water absorption was found to reduce. It was also found that durability of fly-ash concrete containing $38 \%$ fly-ash and $2 \%$ cement replaced by NS was more than that of normal concrete [18].

Fifteen cement paste and concrete mixtures with incremental replacement of fly-ash and four different percentages of nano-silica [19]. It was observed that with time the addition of nano-silica accelerated the reactivity. The optimal ratio of $5 \%$ nano-silica with $15 \%$ fly-ash was chosen as best according to interfacial transition zone (ITZ), water absorption and sorptivity coefficient of concrete. Experiments were performed with 0, 40 and 60\% fly-ash to replace Portland cement. The samples were tested with and without nano-silica. Compressive strength tests and static modulus of elasticity results demonstrate that very small dosage of nano-silica significantly improved concrete properties [20]. Experiments were also performed to replace OPC completely with varying percentages of fly-ash, nano-silica, granulated blast furnace slag (GBFS) and hydrated lime as cementitious additives [21]. It was suggested that $5 \%$ nano-silica was the optimal value for usage as increasing the nano-silica content further resulted in micro-cracks, thereby preventing strength gain. Observations were made that silicious hydrogarnets increases with increase amorphous nano-silica, but it decreased with increase in hydrated lime content.

It was found that concrete produced by mixing 58\% OPC, $40 \%$ fly-ash and $2 \%$ nano-silica had high early compressive strength [22]. Addition of nano-silica enhanced early stage C-S-H gel formation and also reduced calcium hydroxide, porosity further showing increase in compressive strength. Influence of different dosage of nano-silica on strength and microstructure of steam cured fly-ash cement mortar with 50\% replacement of cement by fly-ash was studied [23]. Flexural and compressive strength revealed that nano-silica significantly increases the early strength of the fly-ash based cement mortar. This was attributed to high degree of hydration as well as pore refinement.

\section{Methodology}

Based on the above literature, the present research tries to study the effect of strength and durability nano-silica on HVFAC. The used class F fly-ash was obtained from National Thermal Power Corporation (NTPC), Kahalgaon, India. The Figure 1 shows step-by-step stages in which the research was carried out.

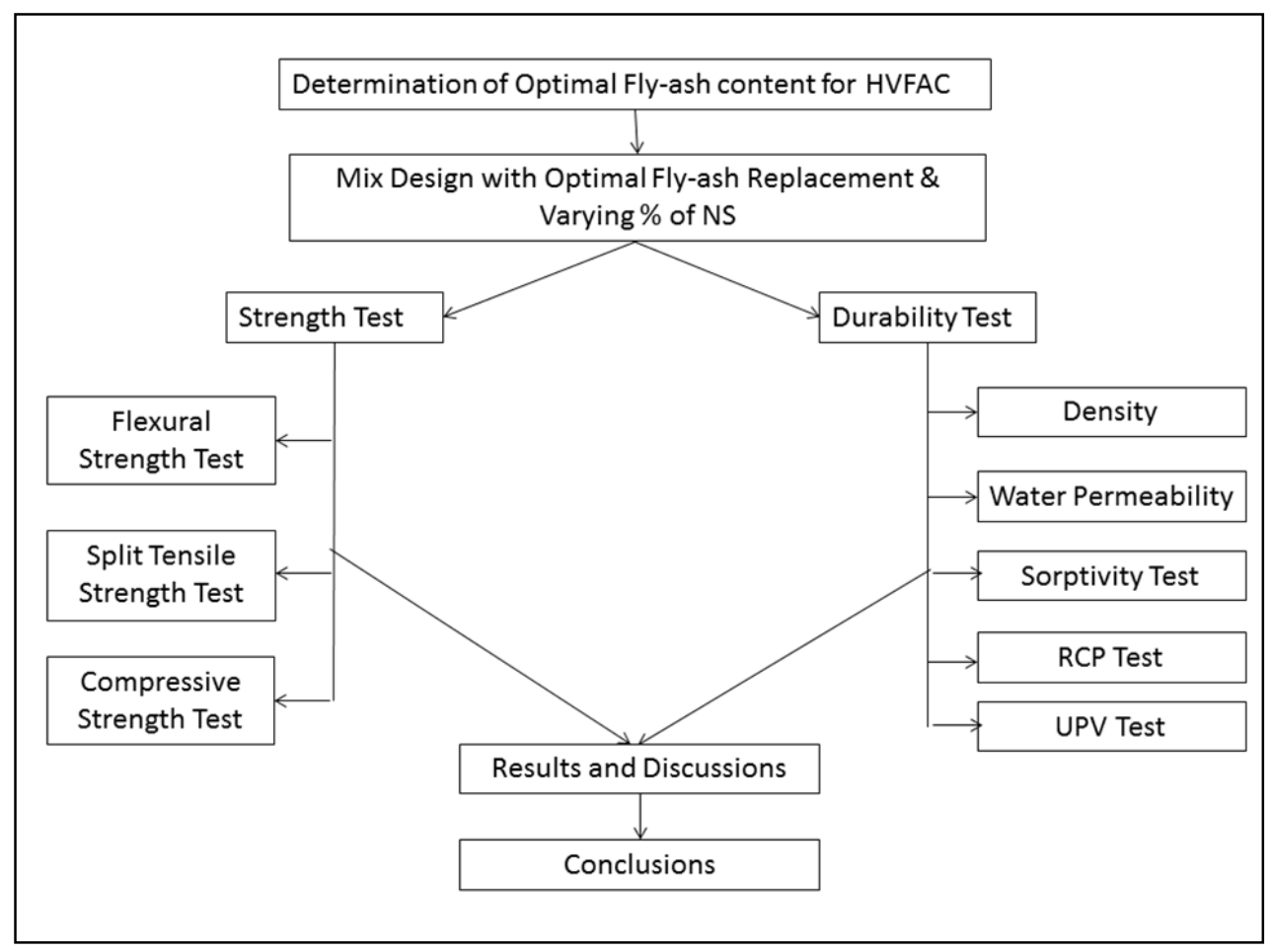

Figure 1. Methodology adopted for conducting the research 
The plot, as given in Figure 2, indicates that the 28 / 90 days characteristic strength of the HVFAC having 55\% and $50 \%$ replacement by F-type fly ash comes to 22/42.6 MPa and 22.8/43 MPa respectively. As the 28 days and 90 days characteristic compressive strength for both cases are nearly equal, hence, the concrete having $55 \%$ replacement of cement by fly ash has been taken up in the present study as it utilizes more quantity of fly-ash and thus is more sustainable.

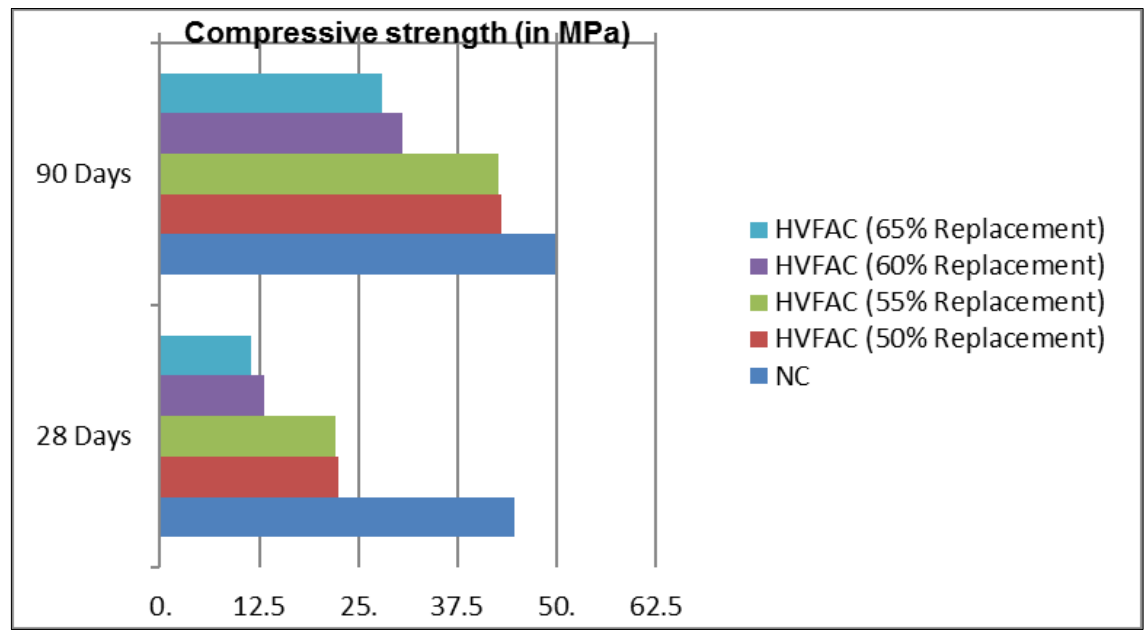

Figure 2. Characteristic compressive strength of different types of concrete with varying replacement of cement by fly-ash for HVFAC

The concrete mix proportioning in the present study was carried out based on the requirement laid by IS 10262: 2016 and IRC: 44-2008. The mix proportions of both normal concrete (NC) and High Volume Fly Ash Concrete (HVFAC) by weight (in $\mathrm{Kg}$ ) are shown in Table 1.

Table 1. Designed mix proportions for NC and HVFAC

\begin{tabular}{ccccccc}
\hline & $\begin{array}{c}\text { Cement } \\
\text { (OPC-43 Grade) }\end{array}$ & $\begin{array}{c}\text { Fly-Ash } \\
\text { (Class F) }\end{array}$ & $\begin{array}{c}\text { Coarse } \\
\text { Aggregate }\end{array}$ & $\begin{array}{c}\text { Fine Aggregate } \\
\text { Zone II }\end{array}$ & $\begin{array}{c}\text { Chemical Admixture } \\
\text { (Superplasticizer) }\end{array}$ & Water \\
\hline NC & 383.13 & Nil & 1102.75 & 727.67 & 0.76 & 153.25 \\
\hline HVFAC & 189.6 & 231.8 & 1085.8 & 716.5 & 0.76 & 153.25 \\
\hline
\end{tabular}

After the fly-ash content was fixed at 55\%, the subsequent samples were modified with nanosilica with varying percentage of 1, 2 and $3 \%$ by weight of cementitious material. Thus, samples were named as Normal concrete (NC), concrete with 55\% cement replacement by fly-ash as High Volume Fly Ash Concrete (HVFAC), HVFAC with $1 \%$ added Nanosilica (HVFAC $+1 \% \mathrm{Nano} \mathrm{SiO}_{2}$ ), HVFAC with $2 \%$ added Nanosilica $\left(\mathrm{HVFAC}+2 \% \mathrm{Nano} \mathrm{SiO}_{2}\right)$ and $\mathrm{HVFAC}$ with $3 \%$ added Nanosilica (HVFAC $+3 \%$ Nano- $\mathrm{SiO}_{2}$ ). The nano- $\mathrm{SiO}_{2}$ used was obtained from NanoLab Pvt. Ltd which also provided specifications of the material as given in Table 2.

Table 2. Specification of $\mathrm{Nano}^{\mathrm{SiO}_{2}}$ obtained from Nano Lab

\begin{tabular}{cccccccc}
\hline $\begin{array}{c}\text { Average particle } \\
\text { size (APS) }\end{array}$ & $\begin{array}{c}\text { Specific Surface } \\
\text { Area (SSA) }\end{array}$ & Colour & Morphology & True Density & Bulk Density & Melting Point & Molar Mass \\
\hline $50-80 \mathrm{~nm}$ & $200-600 \mathrm{~m}^{2} / \mathrm{g}$ & White & Porous & $2.5 \mathrm{~g} / \mathrm{cc}$ & $0.1 \mathrm{~g} / \mathrm{cc}$ & $1600{ }^{\circ} \mathrm{C}$ & $60.08 \mathrm{~g} / \mathrm{mol}$ \\
\hline
\end{tabular}

The percentage of components presents in the Nano $\mathrm{SiO}_{2}$ was provided along with the UV spectrometer analysis. SEM images were provided to identify the particle size of the Nano $\mathrm{SiO}_{2}$ (Table 3 and Figure 3).

Table 3. Component analysis of $\mathrm{Nano}_{\mathrm{SiO}}$ provided by Nano Lab

\begin{tabular}{ccccc}
\hline $\mathbf{S i O 2}$ & $\mathbf{A l}$ & $\mathbf{F e}$ & $\mathbf{M g}$ & $\mathbf{C a}$ \\
\hline $99.5 \%$ & $0.02 \%$ & $0.05 \%$ & $0.1 \%$ & $0.08 \%$ \\
\hline
\end{tabular}




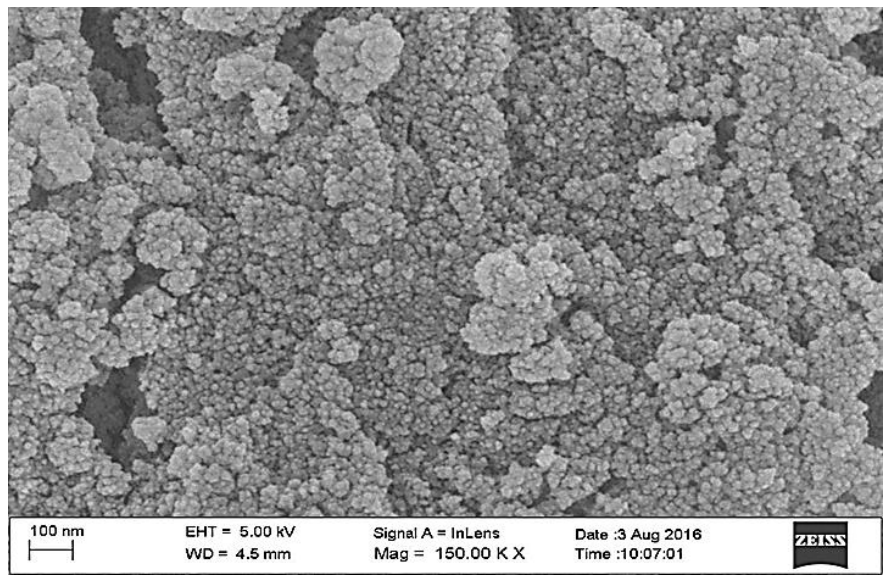

Figure 3. SEM images of nano $\mathrm{SiO}_{2}$ (provided by Nano Lab Pvt. Ltd.)

In the present study, following tests have been conducted to evaluate the strength and durability parameters. Strength parameters are very essential for any construction material. Similarly increased durability of any material suggests improved resistance against weathering, abrasion or chemical attacks which becomes significant exposure conditions.

\section{The tests for strengths are:}

- Flexural strength test

- Compressive strength test

- Split tensile strength test

\section{The tests for durability are:}

- Density

- Permeability

- Sorptivity test to determine Absorption and initial sorptivity

- Pulse velocity

- Rapid Chloride Penetration tests (RCPT)

\section{Results and Discussion}

\subsection{Strength Tests}

The strength tests were performed with varying percentage of nano-silica. The samples were prepared and tested on $7^{\text {th }}$ day, $28^{\text {th }}$ day, $56^{\text {th }}$ day and $90^{\text {th }}$ day.

\subsection{Flexural Strength Test}

It is one of the most important parameters when pavement quality concrete (PQC) is concerned as the pavements has to resist mostly the flexural effects generated by traffic loads. It is conducted on concrete beam specimen $(500 \times 100 \times 100$ $\mathrm{mm}$ ) by three point loading method where the sample is placed on two supporting pins at a fix distance apart and one point loading pin s moving downward from above at a constant rate until sample failure. It is conducted as per ASTM C78.

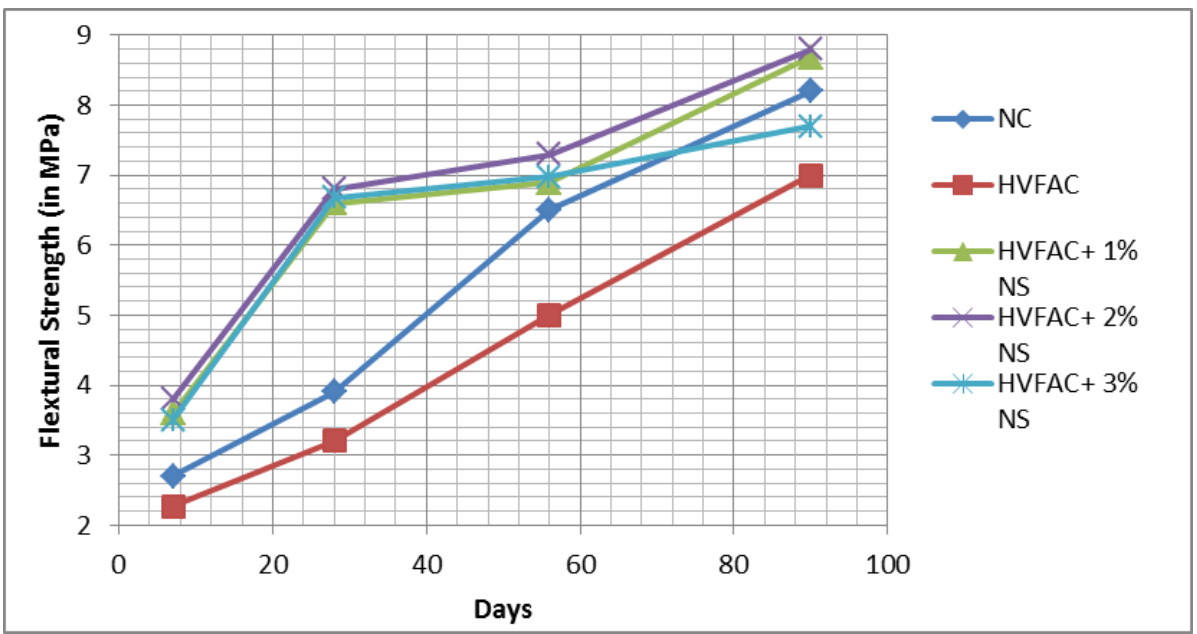

Figure 4. Variation of flexural strength for NC, HVFAC and HVFAC modified with 1, 2 and $3 \% \mathrm{Nano} \mathrm{SiO}_{2}$ at different ages

The results obtained show that the flexural strength of the all samples increased with increase in time. The strength of HVFAC was much less than that of NC. However, with the addition of Nanosilica, the strength kept increasing and maximum strength was obtained for HVFAC $+2 \%$ Nano $\mathrm{SiO}_{2}$. The strength of $\mathrm{HVFAC}$ modified with $2 \%$ nano $\mathrm{SiO}_{2}$ was observed to be even higher than that of $\mathrm{NC}$ even after 28 days and the values after 90 days. 


\subsection{Compressive Strength}

The specimens were tested for compressive strength on compressive testing machine (2000 kN capacity) provided with two steel bearing platens with hardened faces. The load is applied until the specimen ruptures. Cube moulds of 15 $\mathrm{cm}^{3}$ were tested as per IS 516-2004. The results presented here for compressive strength tests are average of three sample of each mix at test age 7,28, 56 and 90 days respectively.

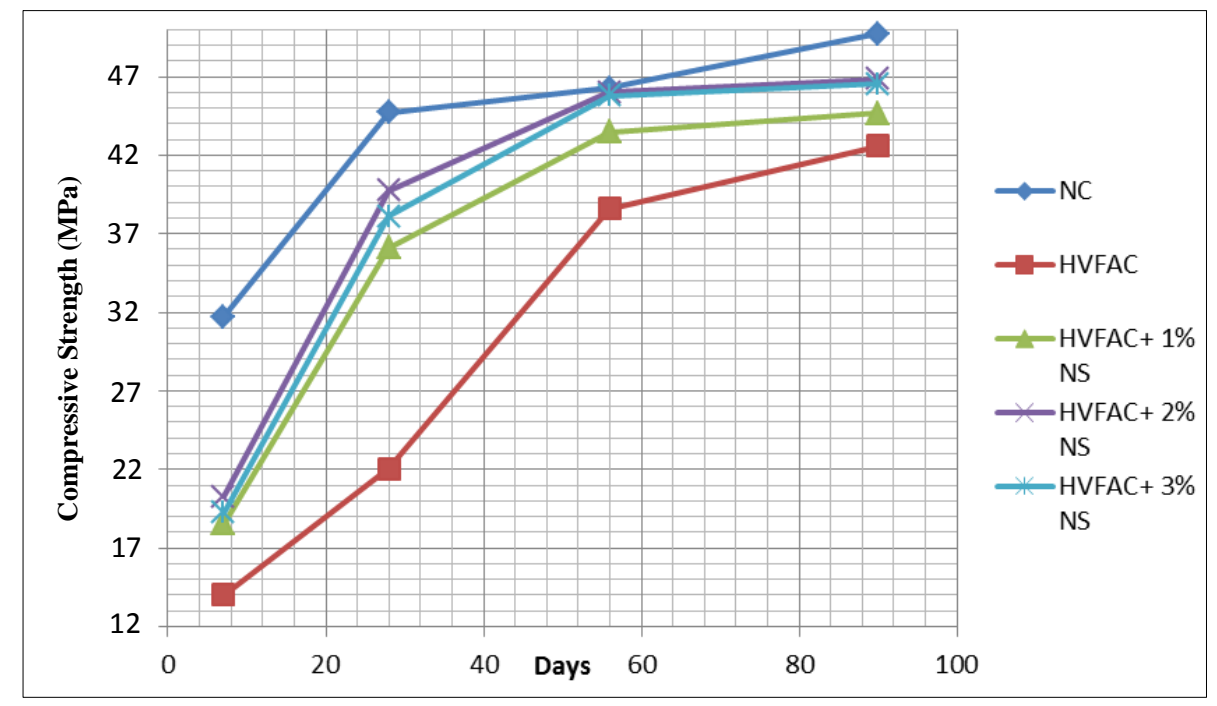

Figure 5. Variation of compressive strength for NC, HVFAC and HVFAC modified with 1, 2 and $3 \% \mathrm{Nano} \mathrm{SiO}_{2}$ at different ages

The compressive strength of NC samples showed the maximum compressive strength whereas the HVFAC showed the minimum strength. Upon modification with Nanosilica, the HVFAC showed an increase in strength wherein the maximum compressive strength for modified concrete was achieved for $\mathrm{HVFAC}+2 \% \mathrm{Nano} \mathrm{SiO}_{2}$. However, the maximum compressive strength equal to NC was achieved only after 56 days.

\subsection{Split Tensile Strength}

Split tensile strength is used to determine the resistance of concrete to indirect tension. The tensile force of concrete is one of the fundamental and important properties as concrete is weak in tension and develops crack when subjected to tensile forces. The test was performed as per ASTM C496. In the present investigation, the split tensile strength test has been conducted on desired grade of HVFAC at 7, 28, 56 and 90 days.

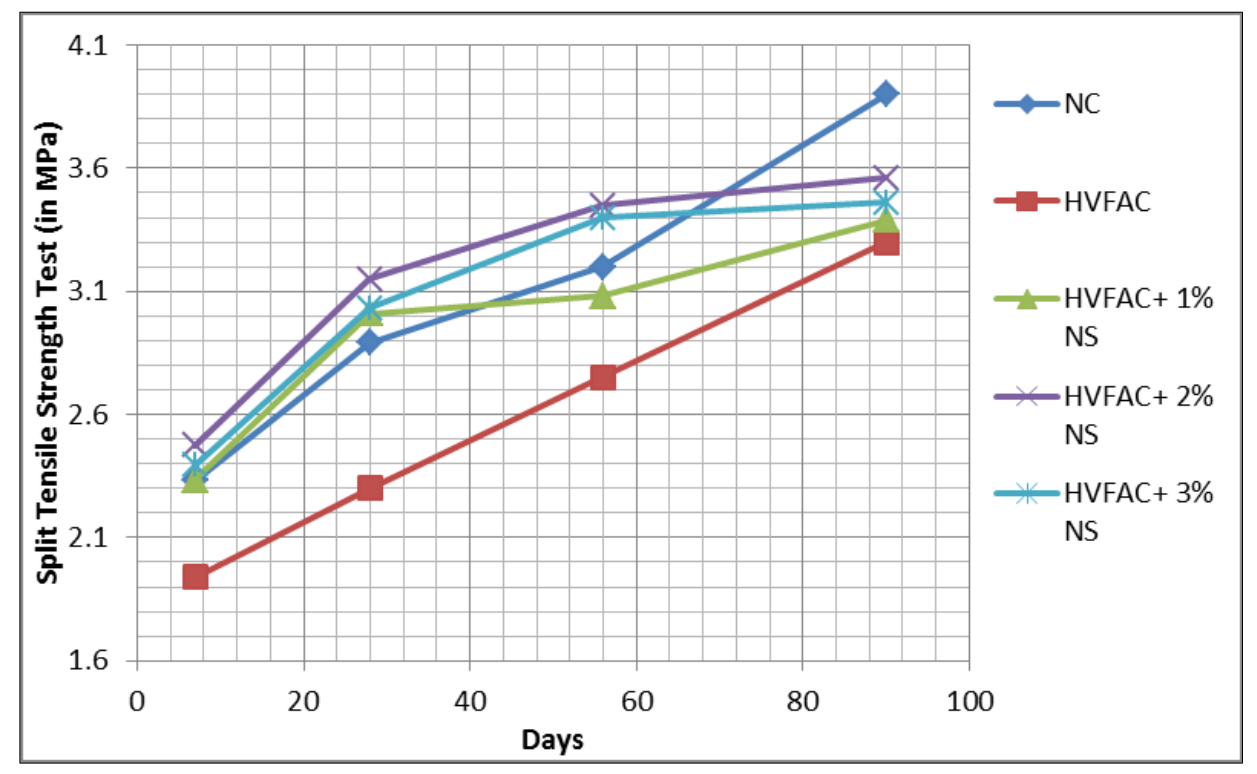

Figure 6. Variation of split tensile strength for NC, HVFAC and HVFAC modified with 1,2 and $3 \mathrm{Nano} \mathrm{SiO}_{2}$ at different ages

Here too, the split tensile strength decreases with introduction of fly ash (HVFAC) as compared to NC. But, addition of Nano silica leads to increase in strength. For the $7^{\text {th }}, 28^{\text {th }}$, and $56^{\text {th }}$ day, $2 \%$ nano silica added samples shows the maximum strength. However, NC regains its strength and showed the maximum strength for 90th day. 
The flexural strength test and compressive strength test increase with addition of nano silica was found by various researchers. Mohamed [23] had observed the increase in strength values with the use of nano silica as binary particles. Isfahani et al. [25] has also observed similar trends with the optimum dosage of nano silica at 1.5 percent. Increase in strength was also found by Supit and Shaikh [18].

\subsection{Durability Tests}

Similarly, durability tests were also conducted on the samples of same composition. The results are presented herein:

\subsubsection{Density}

The weight of the respective concrete cubes are measured which is thereafter checked for density. Density gives us an estimation of the compactness of the mix. The better the compactness of the mix, the durable is the mix. Density is given as mass of the Concrete Cube (m) per unit its actual volume (V).

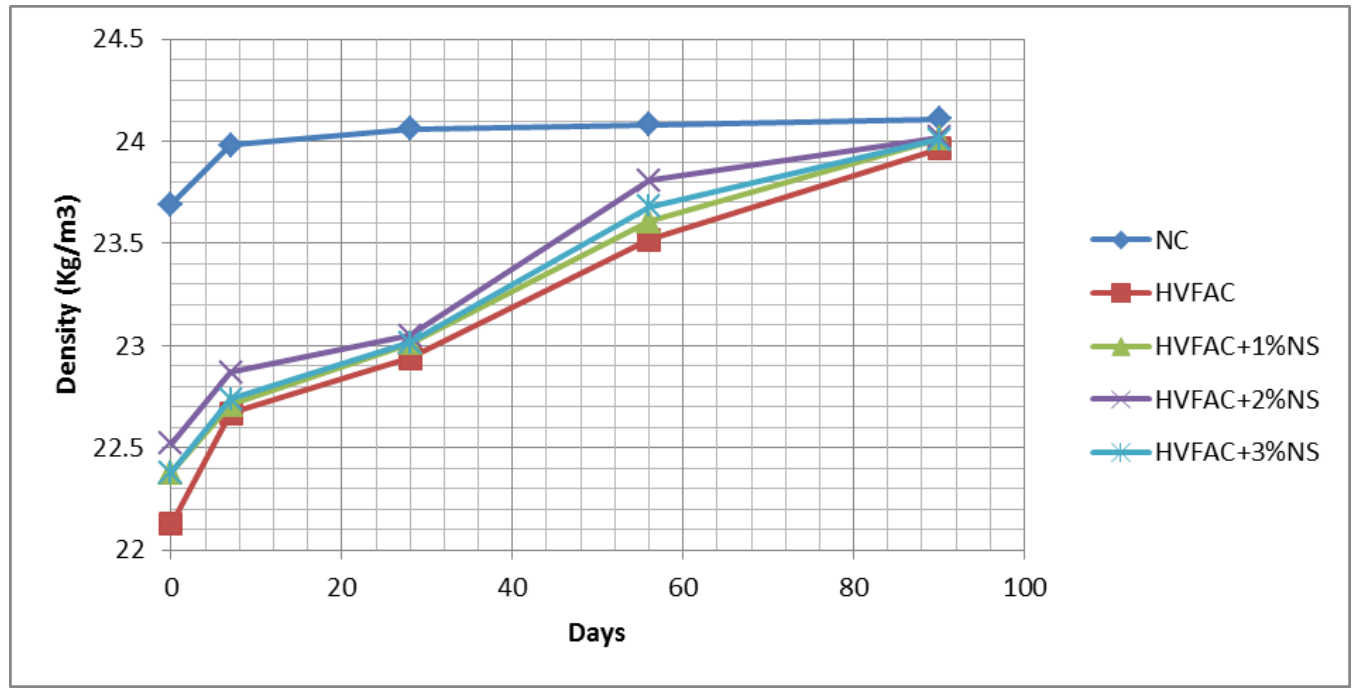

Figure 7. Variation of density for NC, HVFAC and HVFAC modified with 1,2 and $3 \% \mathrm{Nano} \mathrm{SiO}_{2}$ at different ages

In general, there is increase in density with increase in the number of days. However, for NC the density remains constant after a slight increase till about 7 days. For modified HVFAC, the maximum value of density was obtained for $2 \%$ addition of NS in the HVFAC.

\subsubsection{Water Permeability}

This test determines the amount of water percolated through concrete specimen (cube) under applied pressure. On the basis of quantity of percolated water, coefficient of permeability is determined which gives the idea about the durability of concrete. This test is done as per ASTM C577-07.

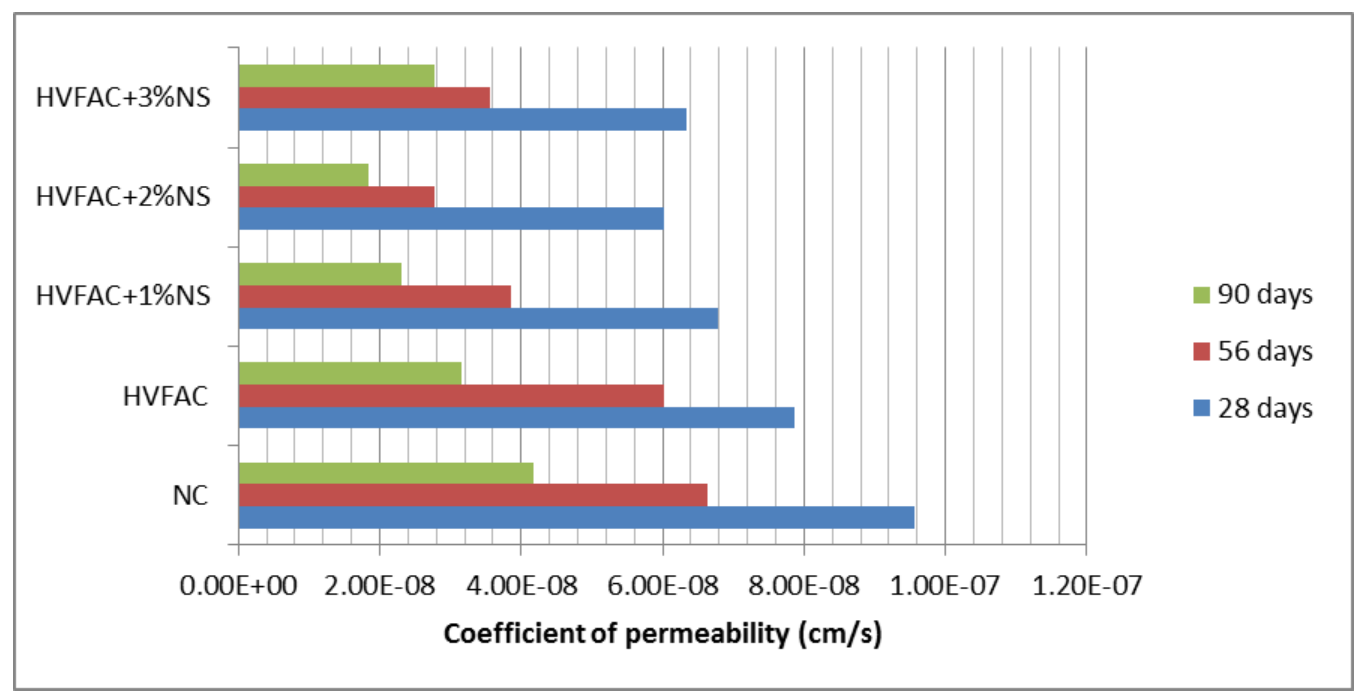

Figure 8. Variation of permeability for NC, HVFAC and HVFAC modified with 1,2 and $3 \% \mathrm{Nano} \mathrm{SiO}_{2}$ at different ages 


\subsubsection{Sorptivity}

Sorptivity is a technique to determine the durability of concrete where the capillary rise in concrete is measured when one face of the cylindrical core specimen come in contact with water surface. This test determines the rate of absorption of water by measuring the gain in the mass of a sample due to capillary suction of water which varies with time as a square root of time when only one surface is exposed to sorption of water. Initial mass of specimen is noted and change in mass due to sorption is measured initially for six hours which is used to determine the initial sorptivity. The measurements for $24 \mathrm{hr}, 2$ days, 5 and 7 days respectively were thereafter recorded. The lesser the sorptivity, better is the concrete. ASTM C1585-13 is used as the standard for conducting the test.

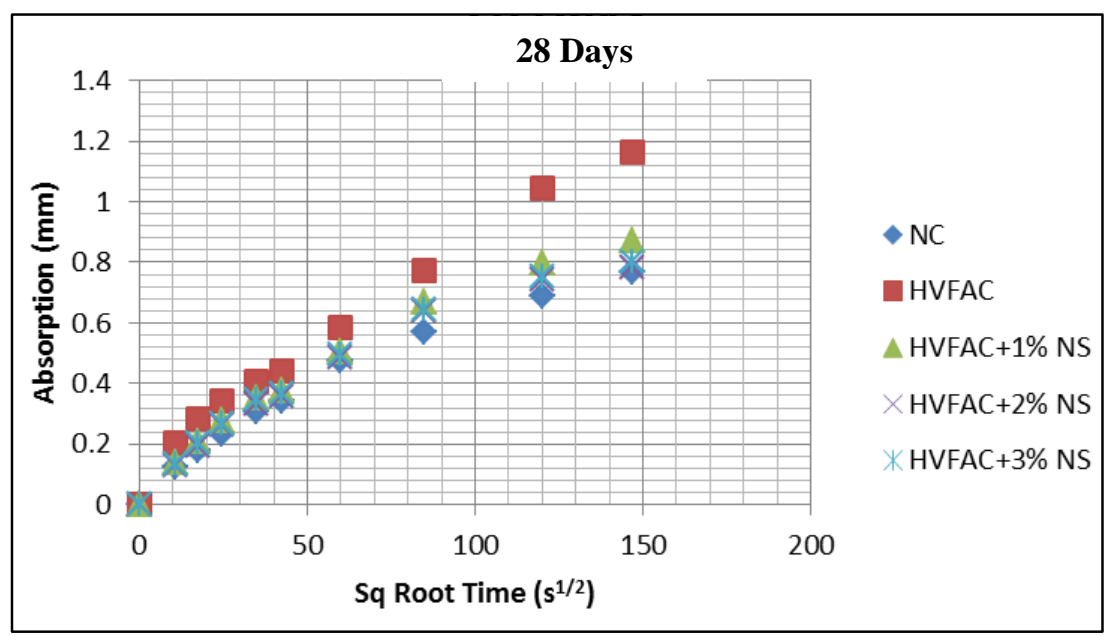

Figure 9. (a) Absorption for NC, HVFAC and HVFAC modified with 1, 2 and $3 \%$ Nano SiO2 at 28 days

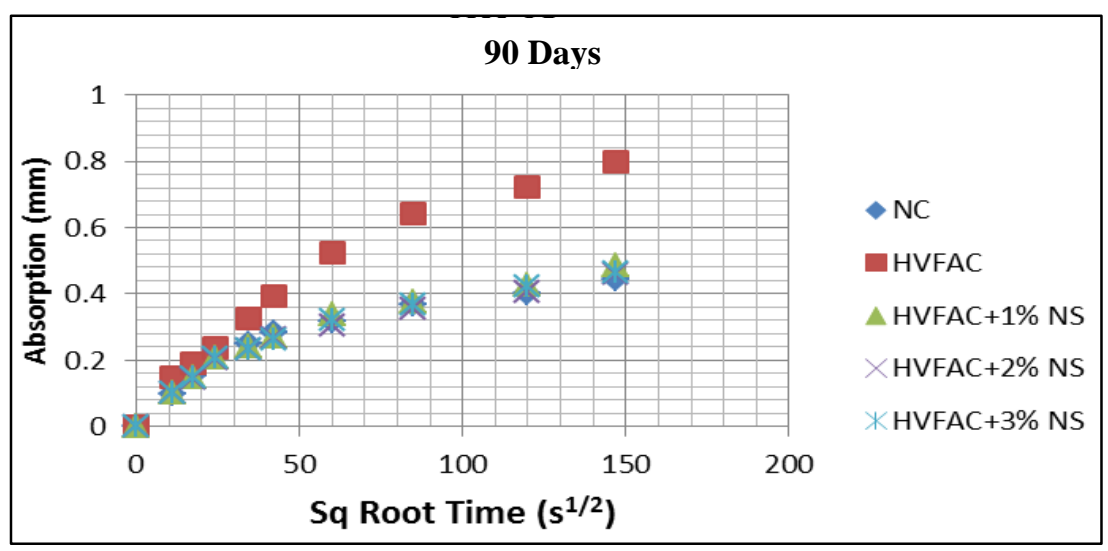

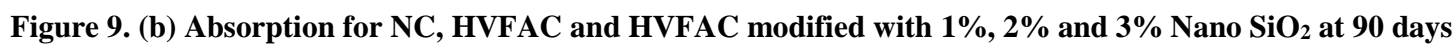

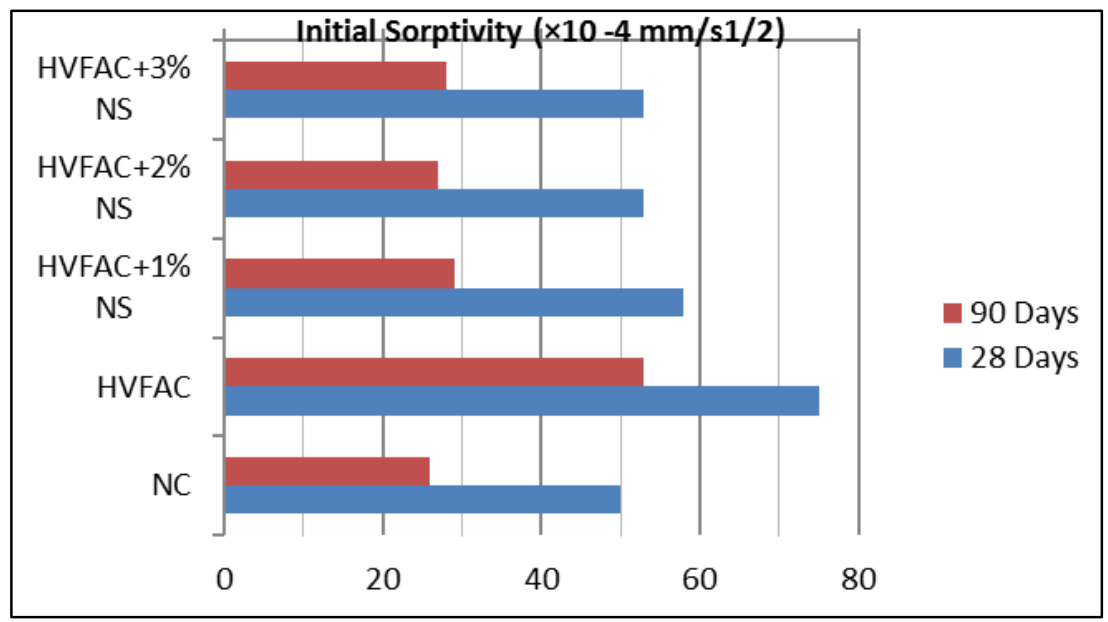

Figure 10. Initial sorptivity for NC, HVFAC and HVFAC modified with 1, 2 and $3 \%$ Nano SiO2 at 28 days and 90 days 
Table 3. Initial sorptivity derived from absorption curves for NC, HVFAC and HVFAC modified with 1, 2 and $3 \%$ Nano $\mathrm{SiO}_{2}$ at 28 and 90 days

\begin{tabular}{|c|c|c|c|c|c|c|}
\hline \multirow{2}{*}{ Sample } & \multicolumn{3}{|c|}{28 Days } & \multicolumn{3}{|c|}{90 Days } \\
\hline & $R^{2}$ & $\begin{array}{l}\text { Equation of Line } \\
\quad \text { (up to } 6 \text { hrs) }\end{array}$ & $\begin{array}{c}\text { Initial Sorptivity } \\
\left(\times \mathbf{1 0}^{-4} \mathrm{~mm} / \mathrm{s}^{\mathbf{0 . 5}}\right)\end{array}$ & $R^{2}$ & $\begin{array}{l}\text { Equation of Line } \\
\quad \text { (up to } 6 \text { hrs) }\end{array}$ & $\begin{array}{c}\text { Initial Sorptivity } \\
\left(\times \mathbf{1 0}^{-4} \mathrm{~mm} / \mathrm{s}^{\mathbf{0 . 5}}\right)\end{array}$ \\
\hline $\mathrm{NC}$ & 0.9547 & $0.005 x+0.0967$ & 50 & 0.8393 & $0.0026 x+01112$ & 26 \\
\hline HVFAC & 0.9817 & $0.0075 x+0.1177$ & 75 & 0.9337 & $0.0053 x+0.1132$ & 53 \\
\hline $\mathrm{HVFAC}+1 \% \mathrm{NS}$ & 0.958 & $0.0058 x+0.1087$ & 58 & 0.8889 & $0.0029 x+0.1017$ & 29 \\
\hline $\mathrm{HVFAC}+2 \% \mathrm{NS}$ & 0.9417 & $0.0053 x+0.1085$ & 53 & 0.8865 & $0.0027 x+0.0095$ & 27 \\
\hline HVFAC $+3 \%$ NS & 0.9436 & $0.0053 x+0.1125$ & 53 & 0.8881 & $0.0028 x+0.1003$ & 28 \\
\hline
\end{tabular}

The initial sorptivity was found for the 6th hour. It was found that $\mathrm{NC}$ had the least initial sorptivity whereas the HVFAC had the greatest value amongst all the combinations. But, addition of NS reduced the sorptivity and for $2 \%$ and $3 \%$ NS addition, the sorptivity reduction was drastic amongst all the modified samples, the value of sorptivity was even compatible with NC.

\subsubsection{Ultrasonic Pulse Velocity Test (UPVT)}

This is a non-destructive test method which is used to determine the material homogeneity, density of concrete and provides information about internal flaws and defects. It consists of measuring the pulse velocity through the concrete to be tested and gives estimation about the durability of concrete. IS-13311-1992 (part I). This test is conducted as per ASTM C 597-16.

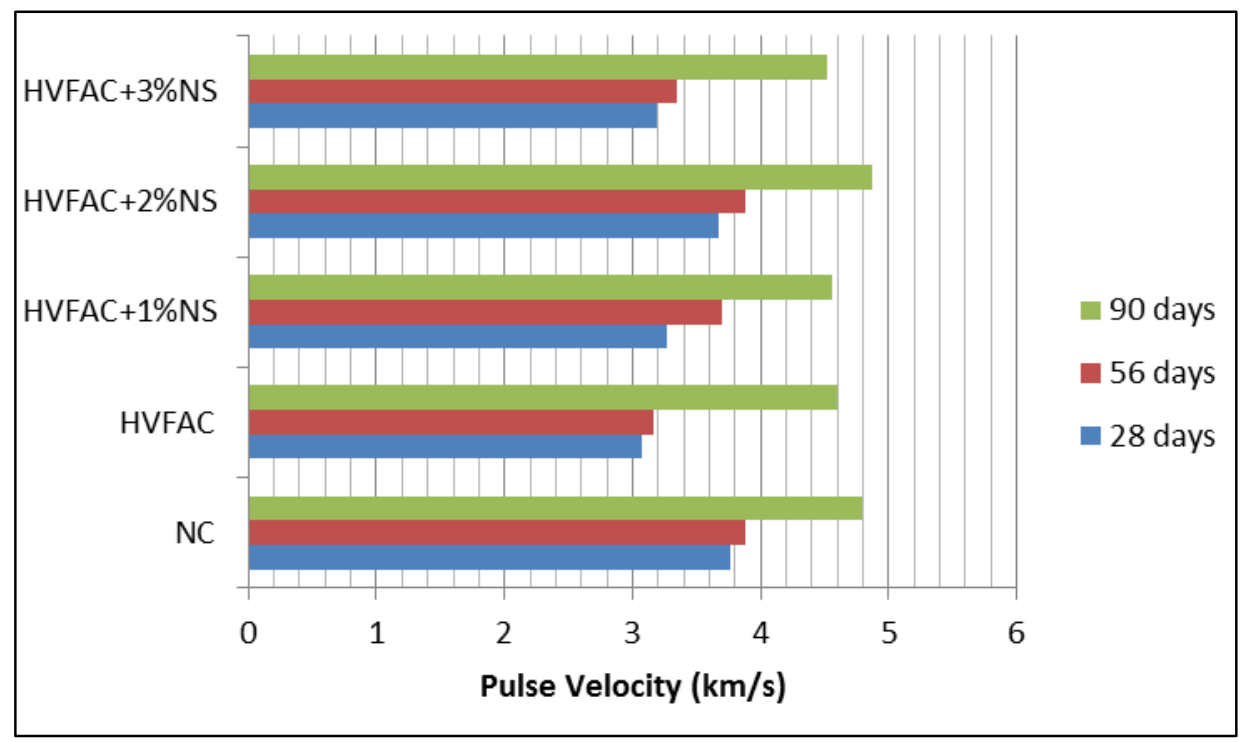

Figure 11. Variation of Ultrasonic Pulse Velocity for NC, HVFAC and HVFAC modified with 1, 2 and $3 \%$ Nano SiO2 at different ages

The results show that the NC and HVFAC $+2 \%$ NS combination have almost overlapping values of pulse velocity. There is increase in the pulse velocity and the pulse velocities for both NC and HVFAC $+2 \%$ NS almost touches a pulse velocity of $5 \mathrm{~km} / \mathrm{s}$ after 90 days, categorizing it under good category from 3rd week to excellent category after 68 days. However, the values are much less for HVFAC and its other combination with NS as shown in Figure 11.

\subsubsection{Rapid Chloride Permeability Test (RCPT)}

It is also a test for durability where in electrical measurement is done where in $60 \mathrm{~V}$ DC voltage is applied for 6 hours to determine the amount of chloride ions that have penetrated into the concrete. The samples are $50 \mathrm{~mm}$ thick with a diameter of $100 \mathrm{~mm}$. The more is the current measured, the more has the chloride ions penetrated into the mix and thereby indicates reduced durability. The test is performed as per ASTM C1202. 


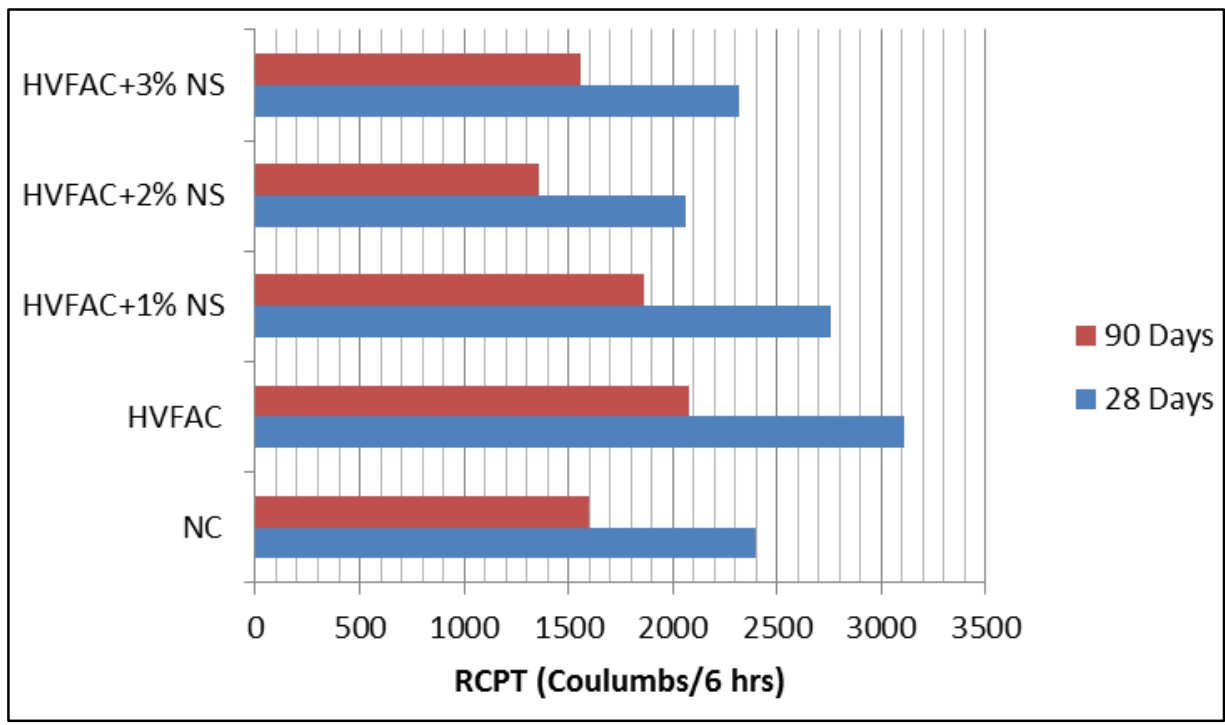

Figure 12. Variation of RCPT for NC, HVFAC and HVFAC modified with 1, 2 and $3 \% \mathrm{Nano} \mathrm{SiO}_{2}$ at 28 and 90 days

Table 4. RCPT values for NC, HVFAC and HVFAC modified with 1, 2 and $3 \% \mathrm{Nano} \mathrm{SiO}_{2}$ at 28 and 90 days

\begin{tabular}{cccccc}
\hline \multicolumn{6}{c}{ RCPT (Coulombs / 6 hours) } \\
\hline & NC & HVFAC & HVFAC + 1\% NS & HVFAC +2\% NS & HVFAC +3\% NS \\
\hline 28 Days & 2396 & 3108 & 2760 & 2065 & 2320 \\
\hline 90 Days & 1598 & 2078 & 1860 & 1356 & 1560 \\
\hline
\end{tabular}

The RCPT tests confirmed the trend obtained through the sorptivity test conducted previously. The result showed that the HVFAC had the highest chloride penetration of 3108 Coulombs after 28 days whereas the introduction of NS reduces the chloride ion penetration. The penetration of chloride ions is lower than NC was observed in case of use of HVFAC with $2 \%$ and $3 \%$ NS. Similar trends were observed for the test conducted after 90 days.

The above results are similar to the results as obtained by Supit and Shaikh [17] who have observed that HVFAC using $2 \%$ NS showed increase in durability on account of decrease in permeability, chloride permeability and sorptivity.

\section{Conclusion}

High Volume Fly Ash Concrete (HVFAC) is a concrete where more than $50 \%$ of the cement has been replaced by fly ash. Present study was carried out by replacing $55 \%$ of cement by fly ash. It was found that both the strength and the durability characteristics of HVFAC is significantly affected by the addition of small amount of NS.

Flexural tests, compressive strength tests and split tensile strength tests were conducted to determine the strength parameters of the NC, HVFAC and HVFAC modified with NS. Flexural strength was found to be maximum for HVFAC modified with $2 \%$ NS. Similar trends were found for compressive strength tests and split tensile strength and for the NS modified HVFAC, $2 \%$ value was found to be the maximum one. As compared to NC, the flexural strength, which is the most important guiding parameter for the strength of rigid pavements, for $2 \%$ NS+HVFAC was found to be even more than that of NC.

Density, permeability, ultrasonic pulse velocity (UPV), sorptivity, and rapid chloride permeability test (RCPT) was conducted to assess the durability aspect of the samples. Apart from density, the $2 \%$ NS modified HVFAC samples and NC had compatible values for all the other parameters showing that durability of the HVFAC might be low, but NS modification enhances the durability of the samples to a significant higher value.

Thereby it can be concluded that $2 \%$ addition of NS for $55 \%$ fly ash containing HVFAC fits proper to be used as pavement quality concrete (PQC). It has been observed through a series of experiments that HVFAC+2\% NS would satisfy the strength and durability requirements for preparation of pavement concrete.

More number of tests needs to be conducted to assess the strength and durability characteristics for different percentages of fly ash with different water-cement ratio in order to come up with definite conclusions for use of such materials with modification with nano silica and other such materials. This can help for setting up standard norms for the design of concrete mixes meant for pavement construction which utilizes fly ash, a waste material as an important resource for sustainable pavement construction. 


\section{Conflicts of Interest}

The authors declare no conflict of interest.

\section{References}

[1] M.L Gambhir., Concrete Technology, Tata McGraw-Hill publishing Company Ltd., New Delhi, 2013.

[2] World Business Council for Sustainable Development, Cement technology roadmap shows how the path to achieve CO2 reductions up to 24 by 2050, https://www.wbcsd.org/Sector-Projects/Cement-Sustainability-Initiative/News/Cement-technologyroadmap-shows-how-the-path-to-achieve-CO2-reductions-up-to-24-by-2050.

[3] The Statistics Portal, Major countries in worldwide cement production from 2012 to 2017 (in million metric tons), https://www.statista.com/statistics/267364/world-cement-production-by-country.

[4] National Thermal Power Corporation (NTPC), Fly Ash: A Resource Material for Construction Sector, NTPC Ash Management Group, 2016, Noida, India.

[5] P. K Mehta, High Performance, High Volume Fly Ash Concrete for Sustainable Development, Proceedings of International Workshop on Sustainable development and Concrete Technology, Ottawa, Canada, 2002, pp 3-14

[6] V. Sivasundaram, G. G. Carette, and V. M. Malhotra, Properties of Concrete Incorporating Low Quantity of Cement and High Volumes of Low-Calcium Fly Ash, ACI, SP-114, 1989, pp. 45-71.

[7] S.H. Gebler and P. Kliger, Effect of Flyash on Physical Properties of Concrete, ACI, SP-91, 1986, pp 1-50.

[8] B. Kumar, G.K. Tike \& P.K. Nanda, Evaluation of Properties of High Volume Concrete for Pavements, ASCE, Journal of Materials in Civil Engineering, Oct. 2007, pp 906-911 doi:10.1061/(ASCE)0899-1561(2007)19:10(906).

[9] K. Gopalakrishnan, B. Birgisson, P. Taylor \& N. Attoh-Okine, Nano-technology in Civil Infrastruture A Paradigm Shift, Springer Publications, 2010.

[10] B. Birgisson, A. K. Mukhopadhyay, G. Geary, M. Khan \& K. Sobolev, Nanotechnology in Concrete Materials, Transportation Research Board, Transportation Research Circular E-C170, 2012, Washington D.C.

[11] T. Ji, Preliminary study on the water permeability and microstructure of concrete incorporating nano-SiO2, Cement and Concrete Research, 35(2005), 1943-1947. doi:10.1016/j.cemconres.2005.07.004.

[12] M. Zhang \& H. Li, Pore structure and chloride permeability of concrete containing nano-particles for pavement, Construction \& Building materials, 25 (2011), 608-616. doi:10.1016/j.conbuildmat.2010.07.032.

[13] Lin, D.F., K.L. Lin, W.C. Chang, H.L. Luo, and M.Q. Cai. "Improvements of Nano-SiO2 on Sludge/fly Ash Mortar." Waste Management 28, no. 6 (2008): 1081-1087. doi:10.1016/j.wasman.2007.03.023.

[14] K. Sobolev, I. Flores \& R. Hermosillo, Nanomaterials and nanotechnology for high performance cement composites, Proceedings of ACI Session on Nanotechnology of Concrete: Recent Developments and Future Perspectives, Nov. 7, 2006, pp. 91-118, Denever, U.S.A.

[15] Z Rong., W. Sun, H. Xiao \& G. Ziang, Effects of nanio-SiO2 particles on the mechanical and microstructural properties of ultraHigh performance cementitious composites, Cement \& Concrete Composites, 56 (2015), 25-31. doi: 10.1016/j.cemconcomp.2014.11.001.

[16] G. Quercia, P. Spiesz, G. Husken \& H.J.H. Brouwers, SCC modification by use of amorphous nano-silica, Cement \& Concrete Composites, 45 (2014), 69-81. doi:10.1016/j.cemconcomp.2013.09.001.

[17] R. Madandoust, E. Mohseni, S.Y. Mousavi \& M. Namnevis, An experimental investigation on the durability of self-compacting mortar containing nano-SiO2, Nano-Fe2O3 and nano-CuO, Construction and Building Materials, 86 (2015), 44-50, doi: 10.1016/j.conbuildmat.2015.03.100.

[18] S.W.M Supit \& F. U. A. Shaikh, Durability Properties of High Volume Fly ash Concrete Containing Nano-Silica, MaterialsandStructures, 2015, 48:2431-2445. doi:10.1617/s11527-014-0329-0.

[19] Ehsani, Ahmad, Mahmoud Nili, and Keyvan Shaabani. "Effect of Nanosilica on the Compressive Strength Development and Water Absorption Properties of Cement Paste and Concrete Containing Fly Ash.” KSCE Journal of Civil Engineering 21, no. 5 (December 26, 2016): 1854-1865. doi:10.1007/s12205-016-0853-2.

[20] Labaj, Martin, Rudolf Hela, and Iveta Hájková. "Nanosilica Activated High Volume Fly Ash Concrete: Effects on Selected Properties.” Key Engineering Materials 722 (December 2016): 157-162. doi:10.4028/www.scientific.net/kem.722.157.

[21] Roychand, Rajeev, Saman De Silva, and Sujeeva Setunge. "Nanosilica Modified High-Volume Fly Ash and Slag Cement Composite: Environmentally Friendly Alternative to OPC.” Journal of Materials in Civil Engineering 30, no. 4 (April 2018): 04018043. doi:10.1061/(asce)mt.1943-5533.0002220. 
[22] Sun, Jinfeng, Xiaodong Shen, Gang Tan, and Jennifer E. Tanner. "Modification Effects of Nano-SiO2 on Early Compressive Strength and Hydration Characteristics of High-Volume Fly Ash Concrete." Journal of Materials in Civil Engineering 31, no. 6 (June 2019): 04019057. doi:10.1061/(asce)mt.1943-5533.0002665.

[23] Liu, Min, Hongbo Tan, and Xingyang He. "Effects of Nano-SiO2 on Early Strength and Microstructure of Steam-Cured High Volume Fly Ash Cement System." Construction and Building Materials 194 (January 2019): 350-359. doi:10.1016/j.conbuildmat.2018.10.214.

[24] Mohamed, Anwar M. "Influence of Nano Materials on Flexural Behavior and Compressive Strength of Concrete." HBRC Journal 12, no. 2 (August 2016): 212-225. doi:10.1016/j.hbrcj.2014.11.006.

[25] Torabian Isfahani, Forood, Elena Redaelli, Federica Lollini, Weiwen Li, and Luca Bertolini. "Effects of Nanosilica on Compressive Strength and Durability Properties of Concrete with Different Water to Binder Ratios." Advances in Materials Science and Engineering 2016 (2016): 1-16. doi:10.1155/2016/8453567. 